\title{
Sustainability issues in New Zealand agriculture - and possibilities for collaborative resolution of them
}

\author{
GUY SALMON \\ Ecologic Foundation, PO Box 756 Nelson \\ guy@ecologic.org.nz
}

\begin{abstract}
Individual and group choices are determined by the structure of institutional arrangements, consisting of both conventions and entitlements (Bromley 1989). Four elements of the institutional structure governing agriculture are identified which embody privileges for the sector, and reduce its accountability. These institutions contribute to the growth of types of agriculture with high environmental impact at the expense of agricultural and non-agricultural activities of lower environmental impact. However, these institutions are now unstable in the face of changing societal expectations, and an important question is, how can reforms directed at a sustainable agriculture sector best be advanced? Recent studies of collaborative governance in the Nordic countries highlight the potential for a widely agreed and planned transition toward sustainability in New Zealand agriculture. It is unclear whether traditional attitudes in the sector will allow a collaborative approach to make progress, but a case is made that the institutions of collaboration can be fostered through design and conscious leadership.
\end{abstract}

Keywords: environment, collaborative governance, privilege, institutions, pollution

\section{Introduction}

Growing for Good, the Parliamentary Commissioner for the Environment's report on agricultural intensification released in November 2004 (Parliamentary Commissioner for the Environment 2004) opened a debate around the environmental implications of land use intensification in New Zealand agriculture. The trends it warned of are not new. The report was in effect a warning to avoid the mistakes that have already been made in Europe, North America and North Asia.

The unpaid external costs of UK agriculture in 2000 were estimated at NZ \$610/ha/year, which was $89 \%$ of average net farm income in that year (Pretty et al. 2000). This study's treatment of water pollution damage was confined to costs associated with remediating human drinking water sources and dealing with about 2600 acute pollution incidents per year. In a significant omission from a New Zealand perspective, the cost to recreational users of degraded water and eutrophic conditions was not estimated. Had it been included, the total unpaid external costs of UK agriculture might have been shown to exceed total farm income.

Once land use intensification has severely degraded water quality, the effects are slow, difficult and costly to reverse, as is shown by the experience of Denmark (Salmon 2006). That country adopted its first Action Plan for the Aquatic Environment in the mid-1980s with the objectives of reducing national phosphorus flows to waterways by $80 \%$ and reducing national nitrogen flows by $50 \%$. Twenty years later, those objectives appear to have finally been achieved, but it required stringent, sustained, intrusive and costly environmental regulation of agricultural activities. In Denmark, every farm is required to obtain annual farm plan approvals from the Danish equivalent of the Department of Conservation. In 1999 the Danish Farmers Union estimated that compliance costs associated with this type of regulation of agriculture were in the range of NZ\$12 000 to $\$ 40$ 000 per farm, per year. Because of ecosystem lag effects, $70 \%$ of Denmark's lakes and $56 \%$ of its rivers and streams still fail to meet the water quality objectives established in regional plans. Persisting eutrophication means the abundance of crustaceans in Danish coastal waters is still at only half their 1980 level.

New Zealand had hitherto been complacent about the environmental risks of land use intensification, apparently because of a mistaken belief that such damage is only likely to occur in countries where agricultural output is subsidised. Growing for Good highlighted that New Zealand is heading down a similar path to European countries, notwithstanding our emphasis on grassland agriculture, and our apparent lack of farm subsidies. In fact, an absence of subsidies cannot really be claimed for New Zealand, since failing to charge farmers for external environmental costs is in itself a form of subsidy. This reality has recently become more transparent with the explicit valuation of New Zealand's Kyoto Protocol liability in the Crown Accounts, a liability to which the growth of dairy farming in particular has made a major contribution.

There is evidence that New Zealand is now approaching a turning point in relation to society's tolerance of the environmental impacts of agriculture. In particular, after 15 years of stalling, and despite the fart tax protest, the agriculture sector has finally been forced to accept responsibility for increases in its greenhouse gas emissions beyond their 2005 level. The events leading 
up to the recent government announcement of climate change policy made it clear that neither the Government nor other economic sectors were prepared to carry the cost of agriculture's emissions indefinitely.

\section{Institutions Influencing Impacts of NZ Agriculture}

Institutions are sets of rules, processes or norms that guide human behaviour (Connor \& Dovers 2002). Individual and group choices are determined by the structure of institutional arrangements, consisting of both conventions and entitlements (Bromley 1989). The institutional framework governing agriculture creates a series of incentives and disincentives that strongly influence agriculture's environmental impacts.

Analysis of the institutional architecture in New Zealand, briefly discussed below, suggests that key elements function to privilege agriculture by exempting it, partially or wholly, from the sustainability constraints which are applied to other economic activities. The results are that agriculture is less accountable for its environmental externalities than other sectors, and that the growth of types of agriculture with high environmental impact has been encouraged relative to agricultural and non-agricultural activities of lower environmental impact. It is beyond the scope of this paper to debate the rationales offered for agriculture's privileged status. Key relevant institutions are:

- the prevailing general exemption of non-point source discharges to the environment from regulation, even though regulation is generally applied to point sources;

- the general failure to charge for environmental externalities;

- the entitlement to use water resources free of charge;

- the non-taxation of capital gains from investing in land.

\section{Exemption of non-point source discharges from regulation}

In New Zealand, pollution is controlled by the Resource Management Act 1991. Section 15 prohibits the discharge of any contaminant into air or water, or to land (in circumstances which may result in that contaminant entering water) unless the discharge is expressly allowed by a rule, a resource consent or regulations. Accordingly, point source discharges are, in general, regulated by regional councils, and good progress has been made in cleaning these up. In contrast, over most of New Zealand, activities giving rise to non-point source discharges, such as fertiliser applications, allowing farm livestock access to waterways, and allowing agricultural land uses which do not comply with land capability parameters for highly erosion-prone land, are commonly facilitated as permitted activities in regional plans. Conditions may apply to these permitted activities, but where such conditions exist, they are rarely enforced. Only in the catchments of a handful of iconic water bodies, notably Lake Taupo and the Rotorua Lakes, has the exemption of non-point source nutrient discharges been reversed. Elsewhere, this exemption, essentially a privilege to agriculture, arguably presents the principal barrier to restoring fishability, swimmability and good ecological health to New Zealand's lowland waterways. Accordingly, the Government's Sustainable Water Programme of Action has identified as a 'key outcome' the need to improve the management of the undesirable effects of land use on water quality (Ministry for the Environment 2006).

\section{Failure to charge for environmental externalities}

The polluter-pays principle has long been recognised throughout the OECD as a key regulatory principle. Full implementation of the principle entails making the polluter pay both for the practical measures required to curb pollution, and for offsetting any residual pollution that could not be eliminated by these measures. In New Zealand, point source dischargers must always meet the costs of pollution control required by their resource consent conditions, and in many cases (though not all) they are also required to make financial contributions under RMA section 108 in respect of any residual discharges. In contrast, non-point source dischargers in the farming sector are in several regions paid subsidies to induce them to undertake pollution-reducing activities such as riparian fencing and erosion prevention plantings. Other than in the proposed plan for Lake Taupo, there are no charges imposed for discharges to water from agricultural activities.

\section{Entitlement to use water resources free of charge}

Water users are generally expected to pay the infrastructure and pumping costs of water, and in some cases, they also pay the administrative costs of water management by regional councils (though these latter costs have often been met from general rates, rather than by water users). Nowhere in New Zealand however, do water users pay a rent for the use of this valuable resource, notwithstanding that there are strong public policy reasons for charging rent for water resources (Scherzer \& Sinner 2006). Water is not a major input into most economic activities, but it is a major input into irrigated agriculture. The agriculture sector accounts for an estimated $77 \%$ of all water allocated for consumptive use in New Zealand (Statistics New Zealand 2004). The exemption from paying rent for water applies generally, and is not specifically directed at agriculture, but the major beneficiaries of this policy are irrigators. Accordingly, the major practical consequence of maintaining a 'free water' policy is to encourage land use intensification, with its associated (largely unregulated) environmental impacts. 


\section{Non-taxation of capital gains}

New investments in intensive dairying appear not to be driven by operating profitability, which for the average New Zealand dairy farm owner-operator was only just over 3\% in each of the last two seasons for which data are available. Rather, they are driven by capital appreciation, which when included yielded a total return on equity of $17 \%$ in $2003-4$ and $32.5 \%$ in $2004-05$ (Dexcel 2006). New Zealand is unusual among OECD countries in exempting capital gains in property from taxation (Tax Review 2001). Since 1990, average dairy farmers have received about two thirds of their returns from appreciating land values (Watters 2005). The fact that these returns are tax-exempt is likely to have distorted investment patterns toward the sector, and further stimulated the strong recent increases in land values. Obtaining an adequate return where higher land values prevail requires more intensive land use practices; and when irrigation water is also free of rents and environmental impacts are not charged for, intensification of land use is more likely to occur, and to translate into environmental degradation. Soaring land values in New Zealand's hill country are one of the factors, along with a lack of accountability for accelerated soil erosion, which explain the failure of commercial forestry to displace pastoral agriculture from many erosion-prone hill country sites in recent years. This is unfortunate, as moving more erosion-prone land into forestry would provide a range of environmental benefits.

\section{Signs of change in these institutions}

The Government's September 2007 climate change decisions (New Zealand Government 2007) in effect over-turned the first two of the above-described institutions, in relation to greenhouse gas emissions. This is an important, precedent-setting change, even though farmers retain the privilege of exemption from emission charges until 2013 and will not face the full costs of farm emissions until 2025. The political willingness to put a price on agriculture's greenhouse gas emissions, and to make individual farmers accountable and responsible for the social cost of these emissions, are the first steps in an institutional transformation that can be expected, progressively, to have a major impact on the other main areas of agriculture's environmental footprint: the degradation of water and soil resources.

Growing technical capability to hold land users accountable for the effects of their actions on natural resources is making an important contribution to these institutional changes. But probably the most important factor is that the foundations of agriculture-privileging institutions in New Zealand's popular culture are now shifting. As in Europe and elsewhere, agriculture in New Zealand is losing its 'sacred cow' status. It is increasingly expected to meet the same social and environmental obligations that society places on other economic activities. An interesting question is how this change will be effected in New Zealand.

Over at least the last half-century, economic and environmental reform in New Zealand has proceeded through prolonged periods of entrenched refusal to change, followed by polarised debate and sudden lurches of reform. Carefully planned transitions have been rare, let alone the sort of continuous, collaborative policy innovation that enables progressive countries to adapt to circumstances, seize opportunities and safeguard the long term interests of all sectors of society.

In the Nordic countries, such continuous policy innovation is facilitated by a collaborative style of governance (Salmon \& Zilliacus 2007). Some adaptation of this approach may be the most appropriate way for New Zealand to move toward a sustainable agriculture sector.

\section{Collaborative Governance Practices}

In all cases in Sweden, and in most cases in the other Nordic countries, legislation and major policy initiatives are preceded by multi-stakeholder deliberations. On environmental issues, deliberating groups usually include environmental and business representatives alongside officials, experts and often politicians. When politicians are involved, all parties in the parliament are invited to send representatives. The groups are focused on a defined issue, and aim to devise a policy solution to that issue. They involve the participants in deep immersion, for prolonged periods of time (usually a year or more), in technical information and policy analysis. The deliberating group is furnished with a secretariat with expert policy staff and commonly, a budget for commissioning relevant independent research as well.

The aim is to achieve a consensus, or where that is not possible, then as broad an agreement as possible, with dissenting participants recording their reservations. The drive for consensus elicits from interest group representatives a pattern of behaviour that is relatively unfamiliar in New Zealand. On the one hand, they are in a powerful position to shape policy. On the other hand, their ongoing influence depends on their maintaining good relations with other participants, whose agreement must be obtained for anything to progress. The result is that powerful incentives are operating for the sensible integration of environmental, economic and social policy.

While the term 'consultation' is often used for the process, it commonly places its participants in the role of negotiating policy solutions which by convention are closely followed by the final decision-makers, either governments or parliaments. This means that the system can best be characterised as 'collaborative governance' 
rather than as 'consultation'.

The collaborative governance approach to policymaking has a number of important advantages, including:

- It tends to overcome impasse and speed up the process of adopting effective policy measures for sustainable development

- It creates policy solutions which are durable through changes of government

- It creates a supportive climate for implementation, and can reduce litigation, and the associated uncertainty, delay and cost for investors

- It facilitates agreed interpretations of science, risk and uncertainty

- It increases the influence of science and "rational solutions" in policymaking.

Some factors pre-disposing toward successful collaboration can be identified from studies to date of collaborative governance practices (Salmon et al. in prep). These include:

- A strong focus by leaders (including sectoral leaders) on achieving policy ownership across political parties, government agencies, and stakeholders, by understanding and accommodating the objectives of others

- Credible political commitment to the implementation of consensus outcomes

- Interdependence of the negotiating parties, based on a rough equality of power such that each can block others from achieving their objectives

- Negotiating long term objectives, and allowing time for transition and adjustment to be a key focus of negotiation

- Accountability of negotiators to sectors which are reasonably cohesive

- A supportive political culture, which consistently provides incentives for collaboration and disincentives for breaches of the rules of the game

- Adequate time and resources to enable the participants to engage in a learning process, with a professional secretariat, and an activist chair.

\section{Collaboration and the future of $\mathrm{NZ}$ agriculture}

All New Zealanders have a strong stake in the successful transformation of agriculture - the country's largest export earner - into an environmentally and economically sustainable source of future wealth. Could the key stakeholders negotiate their way through these difficult conflicts and establish an agreed transition over the years ahead? It is unclear whether the pre-disposing conditions are adequately present in this country, where the institutions of policy formation are arguably more conflictual than in the Nordic countries. Nonetheless, New Zealand does have some experience of collaborative governance, in a number of successful cases, and the country's capacity to learn from others, and to re-shape pre-existing institutions, is widely recognised. The institutions of collaborative governance may be a fostered through a learning-by-doing process, in which the key thing is to make a start.

Collaborative leadership styles appear to grow from experience with proportional electoral systems and minority governments, of which all the Nordic countries have long experience. While New Zealand's experience of these dates only from 1996, political leaders who learned their skills under the new system are now starting to emerge. An important point about Nordic institutions of collaborative governance is that they have grown over the years through conscious design and consistent leadership. This is particularly evident in the case of Finland, which had a civil war in 1918 in which the victors imprisoned 74000 of their fellow countrymen. For the next two decades, Finland was in many respects a bitterly divided society, a division that still had a politically mobilising effect until the 1970s. In the postwar period, the need to secure Finnish independence in relation to the neighbouring Soviet Union led to a strong consensus tradition in foreign policy. Since the mid60 s, the consensual approach has gradually spread to other areas of policy making, so that today, Finland appears more consensual than Sweden (Arter 1999). The Finnish experience suggests that collaborative decision-making involves a set of values and skills that gradually can be learned and integrated into a national political culture, however conflictual its point of departure may be (Salmon \& Zilliacus 2007).

\section{REFERENCES}

Arter, D. 1999. Scandinavian Politics Today. Manchester: Manchester University Press.

Bromley, D. 1989. Economic Interests and Institutions The Conceptual Foundations of Public Policy. Oxford: Basil Blackwell. pp 244-5.

Connor, R.D; Dovers, S.R. 2002. Institutional Change and Learning for Sustainable Development. Working Paper 2002/1. Canberra: Centre for Resource and Environmental Studies, Australian National University. Dexcel. 2006. Economic Survey of New Zealand Dairy Farms 2004-2005. Hamilton, New Zealand.

New Zealand Government. 2007. The Framework for a New Zealand Emissions Trading Scheme. Ministry for the Environment and Treasury, Wellington, New Zealand.

Parliamentary Commissioner for the Environment. 2004. Growing for good: Intensive farming, sustainability and New Zealand's environment. Wellington: Parliamentary Commissioner for the Environment.

Pretty, J.N., Brett, C.; Gee, D.; Hine, R.E.; Mason, C.F.; Morison, J.I.L.; Raven, H.; Rayment, D.; van der Bijl, 
G. 2000. An assessment of the total external costs of UK agriculture. Agricultural Systems 65: 113-136.

Salmon, G. 2006. Introducing nutrient management in the Nordic countries. Report to Ministry for the Environment. Nelson: Ecologic Foundation.

Salmon, G.; Zilliacus, K. 2007. Northern Lights: Could we learn collaborative governance from the Nordic countries? pp 4-7. In: Ecologic, Spring 2007.

Scherzer, J.; Sinner, J. 2006. Resource Rent - Have you paid any lately? Ecologic Research Report No 8.
Ecologic Foundation, Nelson, New Zealand.

Statistics New Zealand. 2004. Water: Physical Stock Accounts for the June Years 1995 to 2001 Inaugural Report. p 29. In: Environmental Accounts Series, updated December 2004. Statistics New Zealand, Wellington.

Tax Review. 2001. Issues Paper. p 32. The Treasury, Wellington, New Zealand.

Watters, A. 2005. What will happen to future land values? p112. In: NZ Dairy Exporter June 2005. 